\title{
Conexões
}

\section{Imprensa de educação e ensino e educação física escolar no Brasil (1976-1979): um relato de experiência acadêmica}

Bruno Duarte Rei ${ }^{1}$

\section{RESUMO}

Este texto discute o processo de constituição, bem como os principais resultados e desdobramentos do projeto de pesquisa intitulado Lutas de representações sobre o desenvolvimento de uma prática: a Educação Física escolar brasileira em revista (1976-1979), desenvolvido, entre 2011 e 2013, junto ao Programa de Pós-Graduação em Educação Física da Universidade Federal do Rio de Janeiro. O debate se desenvolve a partir do relato de experiências de pesquisa do autor, que, desde 2008, vêm se dedicando ao estudo de impressos especializados em Educação Física e esportes que circularam no Brasil durante a ditadura militar.

Palavras Chave: Educação física escolar. Imprensa de educação e ensino. Lutas de representações. Ditadura militar (Brasil).

\footnotetext{
${ }^{1}$ Universidade do Estado do Rio de Janeiro

Submetido em: 24 out. 2017

Aceito em: 23 nov. 2017

Contato: br.duarterei@gmail.com
} 


\section{Education and teaching press and school physical education in Brazil (1976-1979): a report of academic experience}

\section{A BSTRACT}

This text discusses the process of constitution, as well as the main results and developments of the research project entitled Lutas de representações sobre o desenvolvimento de uma prática: a Educação Física escolar brasileira em revista (1976-1979), developed between 2011 and 2013, together with the Post-Graduation Program in Physical Education of the Universidade Federal do Rio de Janeiro. The debate develops from the report of research experiences of the author, who, since 2008, have been dedicating themselves to the study of printed material specialized in Physical Education and sports that circulated in Brazil during the military dictatorship.

Keywords: School physical education. Education and teaching press. Representations fights. Military dictatorship (Brazil).

\section{Prensa pedagógica y la educación física escolar en Brasil (1976-1979): un relato de experiencia académica}

\section{RESUMEN}

Este artículo analiza el proceso de constitución y los principales resultados y desarrollos del proyecto de investigación titulado Lutas de representações sobre o desenvolvimento de uma prática: a Educação Física escolar brasileira em revista (1976-1979), desarrollado entre 2011 y 2013, junto a el Programa de Post-Grado en Educación Física de la Universidade Federal do Rio de Janeiro. El debate se desarrolla a partir de experiencias de investigación del autor, que, desde 2008, se ha dedicado al estudio de la prensa especializada en Educación Física y Deportes que circuló en Brasil durante la dictadura militar.

Palabras Clave: Educación física escolar. Prensa pedagógica. Luchas de representaciones. Dictadura militar (Brasil). 
Neste texto, procurarei discutir o processo de constituição, bem como os principais resultados e desdobramentos do projeto de pesquisa intitulado Lutas de representações sobre o desenvolvimento de uma prática: a Educação Física escolar brasileira em revista (1976-1979), desenvolvido, entre 2011 e 2013, junto ao Programa de Pós-Graduação em Educação Física (PPGEF) da Escola de Educação Física e Desportos (EEFD) da Universidade Federal do Rio de Janeiro (UFRJ). ${ }^{1}$ Isso me faz lembrar de 2008, ano em que me vinculei ao Núcleo de Estudos Sociocorporais e Pedagógicos em Educação Física e Esportes (NESPEFE/EEFD/UFRJ) e, consequentemente, ingressei na iniciação científica, sob a orientação da Profa. Dra. Sílvia Maria Agatti Lüdorf. Outro acontecimento marcou a minha trajetória no referido ano: a participação em meu primeiro encontro de estudantes de Educação Física, o XXIX Encontro Nacional de Estudantes de Educação Física (ENEEF), realizado na Escola de Educação Física da Universidade Federal do Rio Grande do Sul.

Foi sobretudo a partir da experiência vivenciada no XXIX ENEEF que passei a me interessar com mais vigor pelas conexões estabelecidas entre Educação Física e Ciências Humanas e Sociais. Sensibilizado com as calorosas discussões travadas no evento, senti uma forte necessidade de estudar história, de um modo geral, e aspectos históricos da Educação Física, mais especificamente. Acreditava que o estudo da história era um possível caminho para uma melhor compreensão de minha área de atuação, assim como de mim mesmo e do mundo em que vivia.

Motivado por essa crença, comecei a desenvolver, ainda em 2008, o meu projeto de trabalho de conclusão de curso (TCC), requisito parcial para obtenção do título de Licenciado em Educação Física pela EEFD/UFRJ. Na ocasião, queria elaborar uma pesquisa que se circunscrevesse em um período que muito me interessava, mas que pouco conhecia: a ditadura militar. ${ }^{2}$ Ingênuo, acreditava que, ao concluir meu TCC, seria um exímio conhecedor do regime militar brasileiro, assim como da configuração da Educação Física durante os seus anos de vigência - ledo engano! No final do ano, já tinha concluído a primeira versão de meu projeto de TCC, que recebeu o título A Revista de Educação Física (1964-1985) e a prática da Educação Física escolar nos anos da ditadura militar brasileira. ${ }^{3}$

\footnotetext{
${ }^{1}$ Gostaria de registrar, nesta nota, um agradecimento à Coordenação de Aperfeiçoamento de Pessoal de Nível Superior (CAPES), pela bolsa de estudos concedida para o desenvolvimento da pesquisa citada.

${ }_{2}^{2}$ A adoção do termo ditadura militar neste trabalho não é fortuita. Assim como Fico (2014), entendo que não é o apoio ou o consentimento que define a natureza dos eventos da história, mas sim a efetiva participação dos agentes históricos em sua configuração. Nesse sentido, creio ser pertinente classificar o golpe de 1964 como de feitio "civilmilitar", pois, além do apoio, ele foi efetivamente dado por civis: governadores, parlamentares, embaixadores, entre outros. Porém, ainda conforme o autor, compreendo que a ditadura subsequente ao golpe foi eminentemente militar. Não à toa, como destaca Fico (2014), muitos dos civis proeminentes que deram o golpe foram, por exemplo, logo afastados pelos militares, justamente porque punham em risco os seus projetos de poder. Para mais informações, ver Fico (2014).

${ }^{3}$ Agradeço, também, à Fundação Carlos Chagas Filho de Amparo à Pesquisa do Estado do Rio de Janeiro (FAPERJ), pela bolsa de iniciação científica concedida para o desenvolvimento da pesquisa mencionada.

Conexões: Educ. Fís., Esporte e Saúde, Campinas: SP, v. 16, n. 1, p. 85-96, jan./mar. 2018. ISSN: 1980-9030
} 
A ideia de analisar a Revista de Educação Física - periódico já bastante conhecido, editado, desde 1932, pela Escola de Educação Física do Exército, com o propósito de divulgar o pensamento militar sobre a Educação Física brasileira ${ }^{4}$ - partiu da Profa. Sílvia Lüdorf, em uma de suas aulas do curso de Metodologia da Pesquisa. Gostei da sugestão. Fiz uma revisão de literatura e percebi que as edições do impresso lançadas durante o regime militar ainda não haviam sido estudadas. Aliás, também percebi que a configuração da Educação Física escolar no período da ditadura militar era muito pouco estudada. Afora os trabalhos de Beltrami (1992) ${ }^{5}$, Taborda de Oliveira (2001) $)^{6}$, Pinto (2003) e Rosa (2006), não detectei, na época, outras pesquisas que tratavam especificamente desse tema. ${ }^{7}$

Meu projeto de TCC tinha um escopo amplo: analisar, em termos gerais, as concepções de Educação Física escolar que, durante a ditadura militar brasileira, foram difundidas pela Revista de Educação Física. A ideia inicial era, mais precisamente, tomar o referido impresso como um objeto material que visava intermediar a relação estabelecida entre os professores de Educação Física e os referenciais pedagógicos relativos a esse componente curricular que o regime militar pretendia implementar no Brasil (1964-1985). Todavia, com o amadurecimento da pesquisa, formulei uma nova proposta de estudo, que desenvolvi, entre 2011 e 2013, como mestrando do PPGEF/EEFD/UFRJ, ainda sob orientação da Profa. Sílvia.

O novo projeto de pesquisa recebeu o título de Lutas de representações sobre o desenvolvimento de uma prática: a Educação Física escolar brasileira em revista (19761979). Seu objetivo foi analisar, entre 1976 e 1979, as tensões entre as concepções de Educação Física escolar expressas na Revista de Educação Física e na documentação oficial referente ao ensino desse componente curricular. A análise da "materialidade" (LUCA, 2008, p. 138-139) das edições do impresso foi fundamental para o redimensionamento do escopo de minha pesquisa, bem como para definição de um novo recorte temporal. ${ }^{8}$ A partir dessa operação metodológica, percebi que o período entre 1976 e 1979 foi o momento em que se concentraram os artigos mais densos sobre Educação Física escolar publicados entre 1964 e 1985. Além disso, notei que essa periodização coincidia com a fase de maior estabilidade do projeto editorial da Revista

\footnotetext{
${ }^{4}$ Para mais informações sobre aspectos do ciclo de vida e da materialidade desse periódico, ver Ferreira Neto, Maia e Bermond (2003).

${ }^{5}$ O estudo elaborado por Beltrami (1992) foi publicado no formato de livro. Para mais informações, ver Beltrami (2006).

${ }^{6}$ O estudo elaborado por Taborda de Oliveira (2001) também foi publicado no formato de livro. Para mais informações, ver Taborda de Oliveira (2003). Para uma resenha do livro de Taborda de Oliveira (2003), ver Rei e Lüdorf (2016).

${ }^{7}$ A configuração da Educação Física escolar no período da ditadura militar ainda continua, por sinal, muito pouco estudada. Em revisão bibliográfica feita recentemente, detectei apenas três estudos afora os já citados: Pinto (2012), Araújo (2011), que também foi publicado no formato de livro (ARAÚJO e SILVA, 2012), e Rei (2013). Para um balanço historiográfico sobre o tema "Educação Física escolar e ditadura militar (Brasil)", ver Taborda de Oliveira (2002) e Rei e Lüdorf (2012).

${ }^{8}$ Para uma análise da materialidade das edições da Revista de Educação Física lançadas entre 1964 e 1985, ver o segundo capítulo de Rei (2013).

Conexões: Educ. Fís., Esporte e Saúde, Campinas: SP, v. 16, n. 1, p. 85-96, jan./mar. 2018. ISSN: 1980-9030
} 
de Educação Física (1964-1985) e, também, com os anos de vigência da Política e do Plano Nacional de Educação Física e Desportos. ${ }^{9}$

Ao analisar mais detidamente as minhas fontes, constatei que, entre 1976 e 1979, havia uma relação estabelecida entre a publicação da Revista de Educação Física e a necessidade de se consolidar as novas orientações para a Educação Física escolar contidas na Política e no Plano Nacional de Educação Física e Desportos. A referida conexão pôde ser percebida com clareza nos editoriais divulgados durante esse recorte temporal, que explicitavam, entre outras coisas, um dos escopos centrais do periódico: pôr em circulação conhecimentos que contribuíssem, de um modo geral, para impulsionar as novas políticas oficiais voltadas para o setor de Educação Física e esportes no Brasil. É o que se pode verificar, por exemplo, na citação a seguir, que é um fragmento do editorial da edição $n^{\circ} 102$ (1977) da Revista de Educação Física:

\begin{abstract}
Inaugurada no Brasil a nova Política Nacional de Educação Física e Desportos através do PNEFD (Plano Nacional de Educação Física e Desportos), cumpre-nos, como educadores físicos, divulgar e pesquisar conhecimentos específicos sobre a matéria a fim de que se possa, realmente, impulsionar e revigorar o estímulo governamental, abrindo caminhos e alargando horizontes às novas conveniências, que se configuram no elevado propósito de bem servir à comunidade desportiva. [...] O nosso empenho é o de saber sempre mais e melhor e, por isso, acreditamos estar cumprindo a nossa missão quando sentimos que estamos evoluindo e contando, cada vez mais, com o apoio dos que convivem com as nossas aspirações (GAY, 1977). ${ }^{10}$
\end{abstract}

Apesar do exposto, não me pareceu ser possível definir a Revista de Educação Física como uma mera propagadora das novas orientações para a Educação Física escolar expressas na Política e no Plano Nacional de Educação Física e Desportos. Nas edições do periódico lançadas entre 1976 e 1979, a maioria dos artigos que tratam do tema "Fundamentos pedagógicos da Educação Física"11 apresenta pontos de vista contrários aos veiculados nesses documentos oficiais. De um total de dezesseis artigos, sete $-43,75 \%$ - podem ser classificados como consonantes às diretrizes contidas nesses documentos; em contrapartida, nove - 56,25\% - podem ser categorizados como antagônicos. Esses dados me ajudaram a compreender que estudar as edições da Revista

\footnotetext{
${ }^{9}$ Em 1975, entrou em vigor a Lei $n^{\circ} 6.251$, instituindo, entre outras providências, normas gerais sobre a organização dos esportes no Brasil. De acordo com o seu artigo $6^{\circ}$, ficou sob responsabilidade do Ministério da Educação e Cultura a elaboração do Plano Nacional de Educação Física e Desportos, atribuindo prioridade a programas de estímulo à prática esportiva de massa, ao esporte de alto nível e a Educação Física e o esporte estudantil. Tal empreendimento deveria ser elaborado conforme as diretrizes da Política Nacional de Educação Física e Desportos, que apresentava como seus objetivos básicos: (a) o aprimoramento da aptidão física da população; (b) a elevação do nível dos esportes em todas as áreas; (c) a implantação e intensificação da prática dos esportes de massa; (d) a elevação do nível técnico-esportivo das representações nacionais; e (e) a difusão dos esportes como forma de utilização do tempo de lazer. Para mais informações, ver Brasil (1976).

${ }^{10}$ Esse editorial foi assinado pelo coronel Alzir Nunes Gay, comandante da Escola de Educação Física do Exército entre 1977 e 1979.

${ }^{11}$ Assim como Schneider (2010), incluí nessa categoria trabalhos que abordam temas que poderiam servir como referência para o professor de Educação Física planejar e/ou executar as suas aulas. Dentro dessa perspectiva, agrupei nesse eixo temático artigos que debatem assuntos como: concepções de Educação Física, possibilidades de intervenções didático-pedagógicas, políticas públicas, legislação, cartas e manifestos de entidades ligadas ao campo da Educação Física, História e Educação Física, Sociologia e Educação Física, Filosofia e Educação Física etc.

Conexões: Educ. Fís., Esporte e Saúde, Campinas: SP, v. 16, n. 1, p. 85-96, jan./mar. 2018. ISSN: 1980-9030
} 
de Educação Física (1976-1979) não significa apreciar exclusivamente a política do regime militar formulada para a Educação Física escolar brasileira. Mais do que isso, tal empreendimento caracteriza-se como uma experiência de análise de "lutas de representações" (CHARTIER, 1988, p. 17) travadas a fim de se conformar e/ou legitimar práticas exemplares daquilo que seus articulistas concebiam como Educação Física escolar.

O debate estava aberto e era marcado pelas disputas travadas por duas correntes de pensamento internacionais: de um lado, adeptos ao Pragmatismo propunham uma abordagem comprometida com o desenvolvimento do esporte de alto rendimento, destacando a relevância da Educação Física escolar para a formação de atletas profissionais; por outro, os filiados ao Dogmatismo preconizavam a formação integral dos escolares, tomando por base a importância da Educação Física - e, de um modo geral, das práticas corporais - para o alcance desse objetivo. Expressa na Política Nacional de Educação Física e Desportos, a seguinte citação nos ajuda a compreender melhor o foco de tais doutrinas, bem como algumas de suas convergências e divergências:

[...] podem ser sintetizadas em duas as doutrinas adotadas pelos países na condução de sua política de desportos: o Pragmatismo, que orienta o indivíduo para o resultado - a competição, e o Dogmatismo, que adota posição diversa, orientando a prática de Educação Física e desportos para fins educacionais. Onde pode ser claramente observada a diferença entre as duas doutrinas é na Educação Física escolar, interpretada pelo Pragmatismo como iniciação desportiva, ao passo que o Dogmatismo estabelece apenas a educação do movimento, até cerca de dez anos. Entretanto, ambas as concepções convergem para a prática da Educação Física ou desporto de massa, derivando daí o desporto de alto nível, característica das competições nacionais e internacionais (BRASIL, 1976, p. 32).

Diante dessas duas orientações concorrendo em relação à construção de uma “cultura escolar" (JULIA, 2001, p. 10) para a Educação Física no Brasil e no exterior, a ditadura militar tomou a sua posição: por meio da Política e do Plano Nacional de Educação Física e Desportos, desenvolveu um modelo híbrido e dito como imune a confrontações, que mesclava fundamentos da doutrina pragmática e da doutrina dogmática. Esse modelo deveria explorar, para efeito imediato, algumas convergências entre o Pragmatismo e o Dogmatismo e optar, a médio e longo prazo, por uma base estritamente dogmática. Em termos práticos, o modelo de Educação Física escolar contido na política e no plano em tela pode ser descrito da seguinte maneira:

[...] a Educação Física estudantil tem início com a educação do movimento, na ênfase aos contatos com a natureza e em exercícios e jogos nos quais o ritmo, o esquema corporal, a organização tempo-espacial e a coordenação são essenciais. A iniciação desportiva começará depois da faixa etária dos dez anos $-5^{\mathrm{a}}$ série do $1^{\mathrm{o}}$ grau -, quando haverá a orientação para as atividades de massa ou para a competição de alto nível dentro do setor escolar. Essas últimas alternativas deverão ser incentivadas de imediato, visando-se à geração de estímulos indiretos para as atividades físicas da educação formal,

Conexões: Educ. Fís., Esporte e Saúde, Campinas: SP, v. 16, n. 1, p. 85-96, jan./mar. 2018. ISSN: 1980-9030 
fechando, assim, o ciclo de motivação e mobilização da população (BRASIL, 1976, p. 40).

Em que pese o intento de se criar um modelo imune a confrontações, as orientações para a Educação Física escolar estabelecidas no Plano e na Política Nacional de Educação Física e Desportos apenas incorporam, nas séries iniciais de escolarização, alguns fundamentos da doutrina dogmática. Aliás, o principal fator de distinção entre ambas as concepções não foi eliminado: o entendimento de que a Educação Física escolar é a base do sistema esportivo nacional e, consequentemente, um espaço privilegiado para o desenvolvimento da iniciação, do treinamento e da detecção de talentos esportivos. Como exemplo, vejamos a seguinte citação, contida na conclusão da Política Nacional de Educação Física:

Entende-se a Educação Física escolar como causa e o desporto de alto nível como efeito, tendo o desporto de massa como intermediário.

[...] Em termos de administração, é evidente que a maior parte dos investimentos deve ser orientada para a Educação Física escolar.

Tal opção, sobremaneira justificada ao nível técnico, poderá, todavia, sofrer dificuldades na implementação, por falta da orientação das pessoas e entidades envolvidas, ainda prioritariamente voltadas para o efeito, isto é, o desporto de alto nível. [...] Acresce que o desporto de massa cobre o hiato observado entre a Educação Física estudantil e o desporto de alto nível, por intermédio das grandes iniciativas de mobilização popular (BRASIL, 1976, p. 53-54).

Como já vimos, a Revista de Educação Física (1976-1979), tão logo foram publicados o Plano e a Política Nacional de Educação Física e Desportos, se assumiu como um projeto editorial que visava pôr em circulação conhecimentos úteis para impulsionar as novas políticas governamentais direcionadas para a área de Educação Física e esportes. Entretanto, juntamente com o ideário oficial, esse impresso também divulgava concepções antagônicas acerca desse componente curricular. É o que se pode observar no exemplo a seguir, que é trecho de artigo assinado por Manoel José Gomes Tubino (identificado como ex-aluno da Escola de Educação Física do Exército), publicado na edição de $n^{\circ} 100$ (1976) do periódico:

$\mathrm{Na}$ perspectiva internacional da Educação Física, qualquer tentativa de justaposição à realidade brasileira, dentro de uma observação das mais preliminares, estaria correndo o perigo de uma total inexequibilidade. Por exemplo, a adoção da orientação pragmática em regiões de pouco desenvolvimento sócio-econômico seria investir sem receber resultados. O nosso ponto de vista de educador não aceita, mesmo em "pólos de excelência" (São Paulo, por exemplo), a implantação pura e simples de um movimento desportivo (orientação pragmática) sem uma implementação paralela de uma Educação Física com todas as suas manifestações de componente educacional (TUBINO, 1976, p. 10).

Dentro dessa perspectiva, o autor avança com seus argumentos:

Nos últimos tempos, temos sido testemunhas de muitos fatos essencialmente pragmatistas e de poucas manifestações dogmatistas. O intercâmbio cultural Brasil-Alemanha de Educação Física, a campanha de São Paulo "Adote um 


\begin{abstract}
Atleta", os projetos de criação de Ministério dos Esportes e Batalhão Desportivo, etc..., [SIC] fortalecem a nossa afirmação de que ainda não existe um posicionamento ideal no Brasil para a criação de uma concepção adequada da Educação Física.

Mas como o governo brasileiro mais do que nunca está visivelmente interessado em enfrentar os problemas da Educação Física nacional, as nossas esperanças estão reativadas para dias melhores (IDEM).
\end{abstract}

Os fragmentos expostos me ajudaram, entre outros exemplos, a entender que a "Revista de Educação Física" (1976-1979) não era um impresso monolítico. Pelo contrário, esse periódico era, com efeito, um espaço aberto para a exposição e o debate de ideias. Ideias essas que, no que diz respeito ao tema "Fundamentos pedagógicos da Educação Física", na maioria dos casos manifestavam posições antagônicas às defendidas pelo regime militar. Em vista disso, me pareceu ser possível afirmar que, mais do que uma porta-voz do regime militar, a Revista de Educação Física caracterizou-se, potencialmente, como um elemento dificultador da implementação das estratégias oficiais de conformação da Educação Física escolar no Brasil (1976-1979). Acredito que, ao pôr em circulação concepções alternativas sobre o componente curricular em destaque, esse impresso gerou, contraditoriamente, condições para que os profissionais da área pudessem se apropriar de fundamentos distintos dos contidos no modelo propagado pela ditadura militar por meio da Política e do Plano Nacional de Educação Física e Desportos. ${ }^{12}$

Cabe destacar que definir a Revista de Educação Física como um potencial elemento dificultador das estratégias oficiais de conformação da Educação Física escolar no Brasil (1976-1979) não significa dizer que ele cumpriu efetivamente com essa função. Para fazer tal afirmação, seria necessário examinar a "apropriação" (CHARTIER, 2002, p. 68) dos conteúdos veiculados nesse impresso. Afinal, em que medida os professores de Educação Física que atuaram no período em tela tiveram acesso às edições da Revista de Educação Física? Dos que tiveram: quais apropriações fizeram das representações difundidas por esse periódico? Poderíamos afirmar que essa publicação exerceu algum tipo de influência na prática pedagógica cotidiana desses docentes? Essas são questões que deixei em aberto ao concluir a minha dissertação de mestrado.

Em que pese os esforços entabulados na pesquisa aqui exposta, bem como na desenvolvida por Taborda de Oliveira (2001) sobre a Revista Brasileira de Educação Física e Desportos, periódico editado pelo Ministério da Educação e Cultura, ${ }^{13}$ reconheço que ambas, juntas, tratam de apenas dois dos treze periódicos especializados em Educação Física e esportes que circularam durante a ditadura militar. ${ }^{14}$ Atualmente,

\footnotetext{
${ }^{12}$ Um debate pormenorizado sobre esse assunto pode ser encontrado em Rei, Soares e Lüdorf (2016).

${ }^{13}$ É importante esclarecer, de acordo com Taborda de Oliveira (2001), que: "até seu número oito (1969) a Revista [...] denominava-se Boletim Técnico e Informativo de Educação Física. Depois seu nome foi alterado para Revista Brasileira de Educação Física e Desportiva (1970), Revista Brasileira de Educação Física (1971) e, finalmente, Revista Brasileira de Educação Física e Desportos (1975, p. 69)" .

${ }^{14}$ Para um catálogo dos periódicos especializados em Educação Física e esportes em circulação no Brasil (19302000), ver Ferreira Neto et al. (2002).

Conexões: Educ. Fís., Esporte e Saúde, Campinas: SP, v. 16, n. 1, p. 85-96, jan./mar. 2018. ISSN: 1980-9030
} 
continuo me empenhando para contribuir com o preenchimento da lacuna citada, por meio do projeto de pesquisa denominado Entre o Pragmatismo e o Dogmatismo: imprensa de educação e ensino e Educação Física escolar no Brasil (1976-1979), ${ }^{15}$ que desenvolvo como doutorando do Programa de Pós-Graduação em Educação da Faculdade de Educação da Universidade do Estado do Rio de Janeiro, sob a orientação da Profa. Dra. Lia Ciomar Macedo de Faria. ${ }^{16}$ No projeto citado, analiso, afora as já estudadas Revista de Educação Física e Revista Brasileira de Educação Física e Desportos, todos os impressos especializados em Educação Física e esportes em circulação no país entre 1976 e 1979 - como já vimos, período de vigência da Política e do Plano Nacional de Educação Física e Desportos.

Minha intenção é verificar em que medida posso estender a hipótese defendida sobre a Revista de Educação Física para a imprensa especializada em Educação Física e esportes em sua totalidade. Estou apreciando, mais especificamente, os seguintes periódicos: Artus/Revista de Educação Física e Desportos (1976-1979), Boletim da Federação Internacional de Educação Física (1977-1979), Esporte e Educação (1977), Revista da Associação de Professores de Educação Física de São Paulo (1978-1979) e Revista Brasileira de Ciências do Esporte (1979).

Ora, quais eram as concepções de Educação Física escolar que disputavam espaço e legitimidade nos referidos impressos? Em que medida, tais concepções se aproximavam do modelo oficial de Educação Física escolar propagado pelo regime militar por meio da Política e do Plano Nacional de Educação Física e Desportos? É possível sustentar que, mais do que uma porta-voz da ditadura militar, a imprensa especializada em Educação Física caracterizou-se, de um modo geral, como um potencial elemento dificultador das estratégias oficiais de conformação da Educação Física escolar no Brasil (1976-1979)? Em resumo, são essas as questões sobre as quais me debruço no momento.

\section{REFERÊNCIAS}

ARAÚJO, Wesley Batista. Educação física escolar no período da ditadura militar em Jundiaí - SP (1964-1985). 2011. Dissertação (Mestrado em Educação Física) Universidade São Judas Tadeu, São Paulo, 2011.

\footnotetext{
${ }^{15}$ Também não é fortuita a adoção, no título desse projeto de pesquisa, do termo imprensa de educação e ensino ao invés do uso da noção de imprensa pedagógica, por exemplo. Como chama a atenção Nóvoa (1997), ao operarmos com esse termo mais abrangente, podemos mobilizar em nossas pesquisas, além da imprensa pedagógica stricto sensu, periódicos especializados, por exemplo, em Educação Física e esportes, assim como em temas ligados, de um modo geral, à educação não-formal, tais como: educação familiar, da mulher, movimentos de juventude, infância etc. Para mais informações sobre o projeto de pesquisa em tela, ver Rei (2015).

${ }^{16}$ Agradeço, novamente, à Coordenação de Aperfeiçoamento de Pessoal de Nível Superior (CAPES), pela bolsa de estudos concedida para o desenvolvimento da pesquisa citada.

Conexões: Educ. Fís., Esporte e Saúde, Campinas: SP, v. 16, n. 1, p. 85-96, jan./mar. 2018. ISSN: 1980-9030
} 
ARAÚJO, Wesley Batista; SILVA, Sheila dos Santos. Professor de educação física e a ditadura militar no Brasil: comandante ou comandado? Jundiaí: Paco Editorial, 2012.

BELTRAMI, Dalva Marin. A educação física na política educacional do Brasil pós1964. Maringá: EDUEM, 2006.

. A Educação física no âmbito da política educacional no Brasil Pós-64. 1992. Dissertação (Mestrado em História e Filosofia da Educação) - Pontifícia Universidade Católica de São Paulo, São Paulo, 1992.

BRASIL. Ministério da Educação e cultura. Lei n ${ }^{\circ}$ 6.251/75. Plano Nacional de Educação Física e Desportos: PNEFD. Brasília, 1976.

CHARTIER, Roger. A beira da falésia: a história entre incertezas e inquietudes. Porto Alegre: Ed. da UFRGS, 2002.

A história cultural: entre práticas e representações. Lisboa: Difel, 1988.

FERREIRA NETO, Amarílio et al. Catálogo de periódicos de educação física e esporte (1930-2000). Vitória: PROTEORIA, 2002.

; MAIA, Ediane de melo; BERMOND, Magda Terezinha. Revista de educação física: ciclo de vida, seção unidade de doutrina e lição de educação física (1932-2002). Movimento, Porto Alegre, v. 9, n. 1, p. 91-118, 2003.

FICO, Carlos. Golpe de 1964: momentos decisivos. Rio de Janeiro: FGV, 2014.

GAY, Alzir Nunes. Editorial. Revista de Educação Física, Rio de Janeiro, n. 102, p. 1, 1977.

JULIA, Dominique. A cultura escolar como objeto histórico. Revista Brasileira de História da Educação, Campinas, n. 1, p. 9-43, 2001.

LUCA, Tânia Regina. História dos, nos e por meio dos periódicos. In: PINSKY, Carla. (Org.). Fontes históricas. São Paulo: Contexto, 2008.

NÓVOA, António. Imprensa de educação e ensino: concepção e organização do repertório português. In: CATANI, Denice Bárbara; BASTOS, Maria Helena Camara. (Org.). Educação em revista: a imprensa periódica e a história da educação. São Paulo: Escrituras, 1997. 
PINTO, Joélcio Fernandes. Memórias de professores/as de Educação Física sobre formação e práticas pedagógicas (1950-1970). 2012. Tese (Doutorado em Educação) Universidade Federal de Minas Gerais, Belo Horizonte, 2012.

Representações de esporte e Educação Física na ditadura militar: uma leitura a partir da revista de história em quadrinhos DEDINHO (1968-1974). 2003. Dissertação (Mestrado em Educação) - Universidade Federal de Minas Gerais, Belo Horizonte, 2003.

REI, Bruno Duarte. Imprensa de educação e ensino e educação física escolar no Brasil (1976-1979): reflexões sobre uma proposta de estudo. Lecturas: educación física y deportes, Buenos Aires, n. 211, p. 1-8, 2015.

REI, Bruno Duarte. Lutas de representações sobre o desenvolvimento de uma prática: a Educação Física escolar brasileira em revista (1976-1979). 2013. Dissertação (Mestrado em Educação Física) - Universidade Federal do Rio de Janeiro, Rio de Janeiro, 2013.

; LÜDORF, Sílvia Maria Agatti. Educação física escolar e ditadura militar no Brasil (1964-1985): balanço histórico e novas perspectivas. Revista da Educação Física/UEM, Maringá, n. 23, p. 483-497, 2012.

Entre a adesão e a resistência: notas sobre educação física escolar e ditadura militar no Brasil. Revista Brasileira de Ciências do Esporte, v. 38, p. 101-103, 2016.

; SOARES, Antônio Jorge Gonçalves; LÜDORF, Sílvia Maria Agatti. Lutas de representações sobre o desenvolvimento de uma prática: a Educação Física escolar brasileira em revista (1976-1979). Educação em Revista (UFMG), Belo Horizonte, v. 32, p. 203-227, 2016.

ROSA, Juliano de Melo da. Nas vozes de um mesmo tempo: a educação física institucionalizada no período da ditadura militar em Cacequi - RS. 2006. Dissertação (Mestrado em Educação) - Universidade Federal de Santa Maria, Santa Maria, 2006.

SCHNEIDER, Omar. Educação Physica (1932-1945): a arqueologia de um impresso. Vitória: EDUFES, 2010.

TABORDA DE OLIVEIRA, Marcus Aurélio. A Revista Brasileira de Educação Física e Desportos (1968-1984) e a experiência cotidiana de professores da rede municipal de ensino de Curitiba: entre a adesão e a resistência. 2001. Tese (Doutorado em História e Filosofia da Educação) - Pontifícia Universidade Católica de São Paulo, São Paulo, 2001. 
TABORDA DE OLIVEIRA, Marcus Aurélio. Educação física escolar e ditadura militar no Brasil (1968-1984): entre a adesão e a resistência. São Paulo: Ed. da USF, 2003.

Educação Física escolar e ditadura militar no Brasil (1968-1984): história e historiografia. Educação e Pesquisa, São Paulo, v. 28, n.1, p. 51-75, 2002.

TUBINO, Manoel José Gomes. Educação Física: meio ou fim. Revista de Educação Física, Rio de Janeiro, n. 100, p. 8-10, 1976. 